\title{
La democracia directa como alternativa a la democracia representativa: algunas lecciones desde la experiencia suiza
}

Eduardo J. Ruiz Vieytez

DOI: https://doi.org/10.47623/ivap-rvap.108.2017.05

\begin{abstract}
Sumario: I. Introducción.-II. La democracia directa como alternativa: el referéndum. II.1. La democracia directa frente a la crisis de la democracia representativa. II.2. La reactivación del debate en el contexto español.-III. Mecanismos de democracia directa en el sistema político suizo.-IV. Los ámbitos problemáticos. IV.1. La participación. IV.2. El populismo. IV.3. Las contradicciones normativas. IV.4. La cultura política suiza. -V. Conclusión.-VI. Referencias.
\end{abstract}

\section{Introducción}

El objetivo de este artículo es valorar una mayor utilización de los mecanismos de democracia directa, y en particular el referéndum, a partir de la experiencia política suiza. En los últimos tiempos varios sectores sociales y políticos han propuesto un mayor y más efectivo uso del referéndum como mecanismo de participación popular y de regeneración democrática en España. Por este motivo, las experiencias acumuladas en otros modelos pueden resultar de gran utilidad a la hora de debatir serenamente sobre esta cuestión. La hipótesis principal es que la utilización frecuente del referéndum en un modelo como el suizo no está exenta de dificultades y problemas políticos y jurídicos.

Para ello, contextualizaremos en primer lugar las demandas actuales de mayor utilización del referéndum como mecanismo de democracia directa, para después centrarnos en el análisis del funcionamiento de esta figura en el sistema político suizo. En este punto, identificaremos cuatro posibles ámbitos problemáticos a partir de la experiencia del país helvético, antes de extraer de dicho análisis unas conclusiones que respondan al objetivo inicialmente planteado. 


\section{La democracia directa como alternativa: el referéndum}

\section{II.1. La democracia directa frente a la crisis de la democracia representativa}

Existe en la actualidad un consenso amplio sobre la idea de que el modelo de la democracia representativa está experimentando un periodo de crisis(1). En particular, la mayor crítica que se realiza a dicho modelo es la insuficiente participación de los ciudadanos en los procesos de toma de decisiones. Existe en consecuencia en las sociedades avanzadas una demanda general de mayor participación (2) o de innovación democrática.

Con el concepto de innovación democrática nos referimos a diferentes mecanismos o arreglos a través de los cuales los ciudadanos pueden involucrarse en mecanismos decisionales distintos de los habituales en la representación tradicional(3). Dentro de esta categoría se engloban a su vez conceptos diferentes, no totalmente excluyentes entre sí, como los de la democracia deliberativa, la democracia participativa y la democracia directa. La democracia deliberativa incluye otros procedimientos diferentes al referendo en los que la deliberación por parte de los ciudadanos se convierte en la base de la legitimidad de las decisiones tomadas. La democracia participativa se distingue en parte por el hecho de que, más allá del procedimiento, importa que la toma de las decisiones se realice a través de la regla de la mayoría. Así, la democracia participativa se refiere a las formas de participación que incluyen directamente a los ciudadanos en los procedimientos representativos institucionales. Por ello, la democracia participativa comparte una parte de su identidad con la democracia directa, y en particular en el caso del mecanismo del referéndum que aquí nos interesa.

De este modo, un sistema democrático es calificado como representativo cuando la participación del pueblo se limita fundamentalmente a la elección periódica de sus representantes; y directo cuando el pueblo también tiene la competencia de sancionar o derogar, por vía de referéndum, actos de instituciones públicas o la posibilidad de desarrollar un proceso que conduzca a la producción de actos con validez jurídico-

(1) TRETTEL, Martina: «The Politics of Deliberative Democracy. A Comparative Survey of the "Law in Action" of Citizen Participation", en Revista de Derecho Político, núm. 94, 2015, pág. 87.

(2) RAMÍREZ NARDIZ, Alfredo: «Más participación igual a mejor democracia? Acerca de la crítica a la democracia participativa», en Revista de Derecho Político, núm. 94, 2015, pág. 188.

(3) SMITH, Graham: Democratic innovations. Designing institution for citizen participation, Cambridge University Press, Cambridge, 2009, pág. 2. 
política. Ahora bien, la mera existencia de instituciones como el referéndum o la iniciativa popular no califican un sistema como democracia directa. El criterio decisivo de la distinción reposa en la relación e independencia entre el ejercicio de competencias del pueblo y la voluntad de los otros órganos del Estado, sobre todo el Gobierno y el Parlamento. Para que una democracia pueda llamarse directa, el momento o las cuestiones sobre las que el pueblo puede pronunciarse de manera vinculante no dependen más que de la voluntad del mismo o de un criterio objetivo sobre el que los otros órganos del Estado no pueden intervenir (4).

Sobre la dicotomía tradicional entre democracia representativa y democracia directa hay todo tipo de opiniones. Así, aumentar los mecanismos participativos en la democracia representativa es para algunos una buena opción de profundización en la democracia, mientras para otros resulta una complicación inconveniente (5). Siguiendo a Marenghi y Alcántara (6), si entendemos la democracia representativa como un mero remedio de la imposibilidad práctica de implantar una democracia directa; si reafirmamos que son los ciudadanos los titulares del poder de decisión y los representados meros transmisores de su voluntad; y si consideramos que los ciudadanos tienen la capacidad para adoptar las decisiones que mejor se adapten a sus preferencias e intereses, resulta lógico pensar que los mecanismos de democracia directa, y en particular el referéndum, deberían ser contemplados y utilizados en la forma más amplia posible. Si, por el contrario, estimamos que la democracia es sólo un mecanismo procedimental para la elección de los representantes; que estos representantes están por norma general mejor preparados e informados que sus representados para las funciones políticas; y que es difícil garantizar la independencia de la opinión pública en las sociedades actuales, concluiremos que resulta más prudente la toma de decisiones a través de instituciones previamente elegidas y que la democracia directa puede conducir a resultados menos deseados. A pesar de la atracción que las democracias participativa o directa conllevan en primera instancia, no es menos cierto que plantean una decisión previa o fundacional (constitucional) que no siempre está o ha estado igualmente abierta (7).

(4) TORNAY, Bénédicte : La démocratie directe saisie par le juge. L'empreinte de la jurisprudence sur les droits populaires en Suisse, Schulthess, Ginebra, 2008, pág. 7.

(5) RAMÍREZ NARDIZ, Alfredo: op. cit., pág. 187.

(6) MARENGHI, Patricia y ALCÁNTARA, Manuel: "Los mecanismos de la democracia directa", en Revista de Derecho Electoral, núm. 4, 2007, pág. 21.

(7) SARTORI, Giovanni: ¿Qué es la democracia?, Taurus, México DF, 2007, pág. 124. 


\section{II.2. La reactivación del debate en el contexto español}

Al igual que en otros países europeos, en España, la crisis económica vivida a partir del año 2007 sirvió de catalizador a la crisis de la democracia representativa y a un movimiento social de rechazo del sistema jurídico-político emanado de la Constitución de 1978(8). La expresión social más mediática de este rechazo se concretó en el llamado movimiento del $15 \mathrm{M}$, a partir de las acampadas ocurridas desde mayo de 2011. Desde el punto de vista político y electoral, el fenómeno eclosionó en las elecciones europeas de 2014 con el éxito de candidaturas novedosas como las de Podemos, Primavera de los Pueblos o Ciudadanos. Este éxito se confirmó en las elecciones autonómicas y locales de mayo de 2015, tras las que estas formaciones accedieron a numerosos parlamentos autonómicos, al tiempo que plataformas o coaliciones políticas plurales que incluían importantes sectores de la izquierda (hasta entonces) no institucional conquistaban la alcaldía de ciudades tan simbólicas como Madrid, Barcelona, Valencia, Zaragoza, Cádiz, Pamplona, Santiago o Coruña. EI cuestionamiento del sistema "tradicional» se confirmaría en las elecciones generales de 2015 y 2016 a través, sobre todo, de las candidaturas de Podemos (y sus coaliciones territoriales) y de Ciudadanos, con la consiguiente quiebra del bipartidismo tradicional.

Varias de estas formaciones y movimientos denuncian el sistema jurídico-político generado por la Constitución de 1978 como carente de fórmulas para la participación política directa de los ciudadanos en los asuntos públicos. Además de aspectos de índole social y económica, se critican fundamentalmente las cuestiones relativas al sistema electoral y la escasez de los mecanismos de democracia directa(9). El concepto de democracia directa se convierte así es una de las ideas más aludidas en no pocas tertulias y debates políticos. Las reivindicaciones de las formaciones emergentes pasan generalmente por el incremento sustancial de los mecanismos de democracia directa como complemento al menos del régimen de democracia representativa propio de una sociedad desarrollada como la española.

Dentro de los mecanismos de democracia directa, el referéndum emerge como el más atractivo de ellos a los ojos de muchos sectores sociales y políticos(10). Otras formas de democracia directa, como las

(8) VÍRGALA FORURIA, Eduardo: "Crisis de la representación y democracia directa en España», en Asamblea: revista parlamentaria de la Asamblea de Madrid, núm. 29, 2013, págs. 11-13.

(9) PRESNO LINERA, Miguel Ángel: "Causas jurídico-constitucionales de la desafección ciudadana hacia el sistema representativo", en TUR AUSINA, Rosario (dir.), SANJUAN, Francisco Javier y CALABIUG, Maria Amparo (coords.): Problemas actuales del Derecho constitucional en un contexto de crisis, Comares, Granada, 2015, pág. 152.

(10) El Tribunal Constitucional distingue en su STC 103/2008, de 11 de septiembre de 2008, entre los instrumentos de democracia directa (referendos, iniciativa legislativa popular y concejo abierto) que 
asambleas populares, resultan de muy difícil realización en espacios superiores al ámbito local. Del mismo modo, la iniciativa legislativa popular se considera una opción débil de participación si no conduce a una decisión vinculante de los ciudadanos. Es por ello que las diversas formas de referendo se convierten en el objeto de reivindicación y de debate. El hecho de que la Constitución española actual sea poco propicia a los mecanismos de democracia directa(11), especialmente el referéndum, sin duda potencia esta aspiración. Al mismo tiempo, los debates en torno al Ilamado "derecho a decidir», inicialmente centrados en la subjetividad política soberana de las nacionalidades, se han extendido a otra suerte de temas en la misma corriente de opinión, lo que ayuda nuevamente a ensalzar el valor del referéndum como elemento taumatúrgico de un posible sistema político renovado(12).

Si bien el referéndum no es el único mecanismo de democracia directa que incorporan los sistemas políticos de nuestro entorno, es cierto que se trata del más visible y del que puede tener mayores efectos en la transformación del sistema político. Un uso más frecuente del referéndum, sobre un elenco más amplio de materias, a iniciativa no exclusivamente de las instituciones, y con carácter vinculante, daría respuesta a una parte del discurso de renovación o de crítica al modelo vigente. En la siguiente reforma constitucional una regulación del referéndum en este sentido sería el elemento principal que pudiera acomodar las visiones que hoy se presentan como alternativas. Por todo ello, es relevante conocer la experiencia de países que utilizan con profusión este mecanismo de participación popular y sopesar los pros y contras del mismo en aqueIlas experiencias (13). Entre éstas destaca la del sistema suizo (14).

encuentran su base jurídica en el artículo 23 de la Constitución, y los instrumentos de participación (consultas populares, presupuestos participativos o jurados), que emanan de los artículos 9.2 y 48 del texto constitucional.

(11) VÍRGALA FORURIA, Eduardo: op. cit., págs. 17-18.

(12) Considérese como ejemplo de este fenómeno la aparición de páginas electrónicas con este objeto como www.porlademocraciadirecta.org, www.democraciarealya.es, o www.referendumya.es.

(13) TIERNEY. Stephen: Constitutional Referendums. The Theory and Practice of Republican Deliberation, Oxford ConstitutionalTheory, Oxford, 2012.

(14) Según Trettel, en el ámbito anglosajón se tiende a implementar y testar experiencias ad hoc de democracia participativa, mientras que en el continente se procura regular instituciones y procedimientos de participación sin haberlos aplicado antes: TRETTEL, Martina, op. cit., pág. 108. Requejo realiza una crítica de diversos tipos de referendos introducidos en Francia e Italia: REQUEJO RODRíGUEZ, Paloma: "Ciudadanos menores de edad", en Revista Española de Derecho Constitucional, núm. 99, 2013, pp. 201-227. También los países de América Latina incorporan en sus ordenamientos constitucionales varios mecanismos de democracia directa: ZOVATTO, Daniel: "Las instituciones de la democracia directa a nivel nacional en América Latina: Un balance comparativo: 1978-2007", en Revista de Derecho Electoral, núm. 4, 2007, págs. 1-51; GÓMEZ CAMPOS, Steffan: «Mecanismos de democracia directa en América Latina: Una revisión comparada», en Revista de Derecho Electoral, núm. 10, 2010, págs. 1-36. 


\section{Mecanismos de democracia directa en el sistema político suizo}

La democracia directa moderna no se encuentra en el origen de la Confederación Helvética pero caracteriza su sistema político actual por comparación a los de su entorno. El suizo es un modelo constitucional que en realidad combina de forma equilibrada los mecanismos de democracia representativa y de democracia directa(15). Es por ello que son varios los autores que prefieren definir el sistema suizo como democracia "semidirecta» (16), o "democracia de referéndum» (17). En cambio, la consideración del modelo suizo como "democracia representativa en la que se introducen instrumentos de democracia directa" (18) parece menos exacta en la medida en que dicha calificación sería válida para la práctica totalidad de los modelos de democracia representativa y no explicita la singularidad constitucional helvética.

La importancia del papel otorgado al pueblo suizo resulta manifiesta ya en el artículo primero de la Constitución(19) y desde el momento en que el mismo texto declara, en su artículo 148.1, a la Asamblea Federal como autoridad suprema de la Confederación, pero «sujeta a los derechos del Pueblo y de los Cantones». La misma Constitución establece unas condiciones mínimas de democracia que los Cantones deben respetar en sus respectivas Constituciones (art 51). Éstas deben ser aprobadas en todo caso por el pueblo del Cantón respectivo y deben poder ser revisadas si la mayoría de su cuerpo electoral así lo solicita.

Los mecanismos de democracia directa, tan característicos del sistema suizo, son, por un lado, la asamblea popular o Landsgemeinde y, por otro lado, el referéndum en sus diversas modalidades y procedimientos (20). La institución más peculiar de Suiza en términos de democracia directa es, sin duda, la Landsgemeinde, pero ésta opera ya solamente en dos cantones (Glaris y Appenzell Rodas interiores), después de haber sido progresivamente abolida en muchos más durante

(15) GONIN, Luc, Droit constitutionnel suisse. Fondements, institutions et défis, Schultthess, Ginebra, 2015, pág. 55.

(16) GRISEL, Etienne : Initiative et référendum populaires. Traité de la démocratie semi-directe en

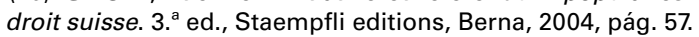

(17) FLEINER, Thomas; MISIC, Alexander y TÖPPERWIEN, Nicole: Constitutional Law in Switzerland. 2. ${ }^{a}$ ed., Wolters Kluwer, La Haya, 2012, págs. 32-34.

(18) SÁENZ ROYO, Eva: «La regulación y la práctica del referéndum en suiza. Un análisis desde las críticas a la institución del referéndum», en Revista de Estudios Políticos, núm. 171, 2016, pág. 74.

(19) SÁNCHEZ FERRIZ, Remedio: «El pueblo de la Confederación Suiza: su significado constitucional y composición", en Revista de Derecho Político, núm. 95, 2016, págs.. 14-15.

(20) SOTO BARRIENTOS, Francisco: “Democracy as a form of state: Analysis of direct democracy' mechanisms regulated by the Swiss constitution", en Estudios Constitucionales, núm. 10-1, 2012, págs. 373-402. 
los siglos XIX y XX. La Landsgemeinde es la reunión de todos los electores de un Cantón y su máximo órgano legislativo. Elige a los miembros de su consejo ejecutivo, aprueba leyes o enmiendas constitucionales, fija impuestos y toma otras decisiones, en función de la evolución política de cada Cantón. En el pasado ejercía también poderes judiciales. Los cantones que se han guiado por este tipo de democracia directa han sido los de predominancia rural, escasamente urbanizados y poblados, y ubicados en el interior del arco alpino septentrional, la zona precisamente originaria de la Confederación. Los principales motivos que han llevado a su progresiva desaparición tienen que ver con razones pragmáticas y logísticas, además de por la complejización social progresiva y por la preferencia del voto secreto frente al público.

Por su parte, el referéndum es un acto decisorio que ejerce el cuerpo electoral. En Suiza, el concepto revela un significado más amplio que la propia votación, pues engloba también el procedimiento que conduce a la misma, por ejemplo, mediante la recogida de firmas. En la época de la antigua Confederación, sin embargo, se denominaba referéndum a la ratificación de las decisiones de la Dieta confederal por las instituciones cantonales. El referéndum actualmente se puede producir a todos los niveles institucionales, esto es, federal, cantonal y municipal. En el plano federal y cantonal pueden someterse a referéndum iniciativas populares o decisiones parlamentarias, pero en el ámbito local pueden también refrendarse decisiones de corte ejecutivo.

El referéndum constitucional, adoptado por influencia del modelo francés (Constituciones de 1793 y 1795), se aplicó por vez primera en 1802, con la votación sobre la segunda Constitución helvética. No se recuperaría esta práctica a nivel federal hasta la constitución de 1848, si bien desde las décadas anteriores numerosos cantones fueron introduciendo diversos tipos de referendos en sus sistemas internos. Las comunas más importantes de Suiza empezarían a introducir el referéndum local a finales del siglo XIX.

A partir de 1848, las revisiones parciales o totales de la Constitución federal son obligatoriamente sometidas a un referéndum. Tras las reformas de 1874, las leyes federales y algunas decisiones federales pueden ser sometidas a un referéndum facultativo. El ámbito original del referéndum fue expandido progresivamente en el siglo $x \mathrm{x}$ al regular el refrendo popular frente a los tratados internacionales concluidos para una duración indeterminada y no denunciables (1921), las decisiones federales urgentes (1949), la adhesión a organizaciones de seguridad colectiva o supranacional (1977) y los tratados internacionales cuya aplicación exige la adopción de leyes federales (2003). Igualmente, la fundación del Cantón del Jura precisó de un referéndum al suponer un cambio en la Constitu- 
ción federal (21). La Constitución de 1999, en su artículo 53, establece un referéndum para toda modificación del número o del estatuto de los cantones, pero ha eliminado la necesidad del refrendo popular para las modificaciones del territorio de los cantones (tras los casos de Laufonnais en 1993 y Vellerat en 1996, derivados igualmente de la creación del Cantón del Jura).

En resumen, podemos distinguir tres tipos de procedimientos conducentes a la celebración de un referéndum federal en el sistema constitucional suizo actual:

a) Iniciativa popular: La iniciativa popular permite a los ciudadanos suizos proponer enmiendas constitucionales, sea mediante la introducción de nuevas disposiciones o por medio de la modificación o derogación de las disposiciones existentes. Para que una iniciativa sea sometida al veredicto de las urnas, sus promotores deben reunir 100.000 firmas de ciudadanos con derecho a voto y presentarlas a la Cancillería Federal en un plazo de 18 meses (art. 139). Esta posibilidad fue establecida en 1874. Para su aprobación, es necesario que se pronuncie a favor de la misma tanto la mayoría de la población federal como una mayoría de los 26 cantones y semicantones.

b) Referéndum obligatorio (art. 140.1): Cualquier supuesto de modificación de la Constitución Federal por el Parlamento debe ser sometido al voto popular y aprobado por mayoría de los votantes y de los cantones. Lo mismo ocurre con la adhesión a organizaciones de seguridad colectiva o a organizaciones supranacionales, así como para la adopción de leyes declaradas urgentes cuya validez supere un año de duración.

c) Referéndum opcional o facultativo (art. 141): Los suizos también tienen la posibilidad de impugnar cualquier ley aprobada o modificada por el Parlamento. Para ello, deben presentar 50.000 firmas de ciudadanos con derecho a voto ante la Cancillería Federal dentro de los 100 días posteriores a la publicación de la ley impugnada. De igual manera puede convocarse un referéndum facultativo respecto a los tratados internacionales concluidos para una duración indeterminada y no denunciables, las decisiones federales previstas en el ordenamiento, la adhesión a organizaciones de seguridad colectiva o supranacional y los tratados internacionales cuya aplicación exija la adopción de leyes federales.

(21) RUIZ VIEYTEZ, Eduardo, “¿Derecho a decidir en clave interna? el conflicto del Jura y el referéndum de 2013», en Revista d'Estudis Autonómics i Federals, núm. 20, 2014, págs. 96-131. 
Desde 1848, se han celebrado en el conjunto de Suiza más de 600 votaciones a través de alguno de estos mecanismos de democracia directa. En cuanto a sus resultados, considerando las tres posibilidades conjuntamente, existe un relativo equilibrio entre las aprobadas y las rechazadas.

\section{Los ámbitos problemáticos}

La amplia utilización del referéndum en el sistema suizo asegura, desde luego, una mayor participación popular en los procesos de toma de decisión y seguramente una mayor conciencia cívica de sus habitantes. Sin embargo, la experiencia suiza muestra otros elementos de preocupación que es necesario analizar. Podemos sistematizar esta problemática en torno a cuatro tipos de elementos o factores diferentes: la participación, el populismo, las contradicciones normativas y la cultura política.

\section{IV.1. La participación}

A pesar de que la mayoría de los ciudadanos suizos se muestran orgullosos de la democracia directa y señalan su relevancia para el porvenir de su país (22), un primer problema que plantea la proliferación de referendos y convocatorias electorales es la baja participación que éstos registran como media. Con carácter general, la tasa de participación en los referendos federales ha caído desde los tiempos de la Segunda Guerra Mundial, de un $60 \%$ a un $40 \%$ de media, estando en la actualidad claramente por debajo de la mitad del censo electoral, una cifra que se antoja escasa en función de la cantidad e importancia de algunas de las decisiones que se adoptan a través de este mecanismo.

Las razones que explican tan baja participación pueden ser objeto de debate e interpretación, destacando como una de las más sencillas el progresivo agotamiento de los ciudadanos ante la proliferación de convocatorias (23), aunque hay también quien insiste en una suerte de especialización y abstención selectiva de los ciudadanos, que no se sienten competentes ante todo tipo de cuestiones en una sociedad mucho más compleja que la de antaño(24). Desde esta perspectiva, la baja participa-

(22) KRIESI, Hanspeter y TRECHSEL, Alexander: The Politics of Switzerland. Continuity and change in a consensus democracy, Cambridge University Press, Cambridge, 2008, pág. 66.

(23) RAMÍREZ NARDIZ, Alfredo: op. cit., pág. 209.

(24) KRIESI, Hanspeter. (dir.): Citoyenneté et démocratie directe. Compétence, participation et décision des citoyens et citoyennes suisses, Editions seísmo, Zurich, 1993, pág. 278. 
ción no sería el resultado de una merma del interés político por participar en la toma de decisiones, sino una muestra de madurez del electorado suizo que selecciona los asuntos sobre los que puede emitir una opinión más formada o interesada. En esta clave podría ser relevante considerar el hecho de que si la media de participación puede parecer baja, no necesariamente lo es el porcentaje de ciudadanos que sí participa cada año en al menos alguna convocatoria de referendo, lo que mitigaría este supuesto problema.

En todo caso, una baja participación media, motivada por unas u otras razones, supone un problema político a la hora de legitimar decisiones muy relevantes para el país. La experiencia suiza muestra que el electorado de cualquier país puede resentirse si es convocado a pronunciarse demasiado frecuentemente, lo que se ha considerado como un "precio a pagar» por la democracia directa(25), si bien ello podría conducir a este modelo a convertirse en lo que algunos Ilaman un espacio sin ciudadanos (26).

\section{IV.2. El populismo}

Un sistema de democracia semidirecta como el suizo también corre el riesgo de adoptar determinadas decisiones importantes sin la dosis adecuada de prudencia o reposo(27). No en vano, determinados discursos populistas pueden disponer en este sistema de un caldo de cultivo favorable que pudiera llevar, incluso, a la adopción popular de iniciativas que vayan claramente en contra de los derechos fundamentales de determinadas personas o colectivos, en nombre de la regla de la mayoría y de la soberanía popular (28). De hecho, la democracia directa parece tener efectos negativos sobre los derechos de las minorías que son consideradas "externas» desde el punto de vista de la mayoría, aunque se trate precisamente de los grupos que necesiten en mayor medida de apoyo del Estado frente a la intolerancia (29).

(25) SÁENZ ROYO, Eva: op. cit., pág. 82.

(26) CABEZA, Laura y GOMEZ FORTES, Braulio: «Referéndums sin ciudadanos. El caso del referendo para la reforma del Estatuto de Autonomía andaluz», en Reis: Revista española de investigaciones sociológicas, núm. 130, 2010, pág. 37.

(27) GONIN, Luc: op. cit., pág. 171.

(28) MALINVERNI, Giorgio: "Démocratie directe et droits de I'homme», en GOOD, Andrea y PLATIDOPIS, Bettina (eds.) : Direkte Demokratie: Herausforderungen zwischen Politik und Recht, Stämpfli, Berna, 2013, págs. 453-454.

(29) CHRISTMANN, Anna y DANACl, Deniz: «Direct Democracy and Minority Rights. Direct and Indirect Effects on Religious Minorities in Switzerland», en Politics and Religion, núm. 5-1, 2012, pág. 155; TIERNEY. Stephen: op. cit., pág. 23. 
Al menos cuatro iniciativas populares aprobadas por el pueblo suizo en los últimos años sirven para ilustrar esta alarma:

a) El 8 de febrero de 2004 los suizos votaron a favor de la iniciativa popular sobre el «internamiento de por vida de los delincuentes sexuales o violentos juzgados muy peligrosos y no reinsertables" (art. 123a de la Constitución)

b) El 29 de noviembre de 2009 el pueblo suizo y los cantones aprobaron por referéndum incorporar a la Constitución la prohibición absoluta de construcción de nuevos minaretes (art. 72.3).

c) El 28 de noviembre de 2010 se aprobó en referéndum la iniciativa popular "por el reenvío de los extranjeros criminales» (art. 121.3 a 121.6)

d) El 9 de febrero de 2014 se aprobaba la iniciativa popular «contra la inmigración masiva», que a su vez contradice acuerdos establecidos con la UE y aprobados en referéndum en el año 2000 (art. 121.a y 197.9)

El resultado de cualquiera de estos referendos, que contradice las directrices emanadas de la mayoría de las fuerzas políticas suizas, así como de sus instituciones federales, puede ser catalogado como un triunfo de posiciones populistas, normalmente impulsadas desde el Partido Popular Suizo (SVP por sus siglas en alemán; su nombre en francés es Unión Democrática de Centro, UDC) y el mucho más minoritario Unión Democrática Federal (EDU-UDF). En particular, el referéndum sobre la prohibición de los minaretes de 2009 fue instigado por ambas fuerzas aprovechando un clima de alarma en algunos sectores sociales ante el aumento del número de mezquitas en el país. Sus promotores justificaban la propuesta sobre la consideración de que los minaretes constituyen símbolos de una reivindicación islámica de poder políticoreligioso que cuestiona el ordenamiento jurídico de Suiza(30). El grupo promotor estaba compuesto por 16 ciudadanos suizos, de los que 14 eran miembros del SVP. Desde una clave política, el resultado del referéndum no debe explicarse desde la cuestión concreta de la construcción de determinados elementos arquitectónicos de uso religioso, sino por un contexto de recelo a una extensión de determinadas formas de

(30) Como contextualización, recordemos que en Suiza habitan más de 1,5 millones de personas de origen extranjero, lo que representa alrededor de un $22 \%$ de su población total, porcentaje superior al de los países que la rodean: GARÇON, François: Le modèle Suisse. 2. ${ }^{a}$ ed., editions Perrin, Paris, 2011, pág. 189. Las estimaciones sobre la población musulmana en Suiza nos llevan a cifras entre 300.000 (FUND, John: "Swiss Stunner», en The American Spectator, febrero 2010, pág. 60) y 400.000 personas (HIRTER, Hans (dir.): Année politique Suisse 2009, Institut de science politique à la université de Berne, Berna, 2010, pág. 13). 
Islam(31). En efecto, los minaretes denotan la presencia de las comunidades musulmanas, alteran el skyline tradicional de las sociedades europeas, y atraen el temor de determinados sectores a un cambio social demasiado profundo, que algunas formaciones políticas capitalizaron a través de esta iniciativa. Según algunos autores, con su decisión, los suizos criticaban una cierta corrección política ante la radicalización religiosa (32). Otros señalan que el debate de fondo no es otro que la integración o exclusión de determinadas minorías(33). En la misma línea, se alude al miedo al cambio(34) o a un supuesto proceso de «islamización” de la sociedad suiza (35).

Solo un año más tarde, la aprobación popular de la iniciativa para la repatriación de criminales extranjeros reforzaba estos mismos temores, además de las contradicciones entre el respeto a los derechos humanos y el Derecho constitucional suizo. El referéndum de 2014 contra la inmigración masiva insistía en los mismos planteamientos de recelo frente a los extraños y de populismo, limitando cuotas para determinadas categorías de inmigrantes y restringiendo las posibilidades de reagrupación familiar, acceso a servicios sociales y al derecho de asilo. Esta última votación trajo como consecuencia medidas de respuesta de la UE, como la exclusión de Suiza de los programas Erasmus y Horizonte 2020.

En varios de estos referendos los sondeos políticos previos anunciaban un triunfo de las posiciones institucionales defendidas por la mayoría de partidos. Sin embargo, el resultado final tras la campaña electoral se acercó más a los deseos del SVP y de las posiciones que podemos identificar como populistas. En realidad, si analizamos el conjunto de las iniciativas populares sometidas a referéndum en los últimos 150 años, podemos comprobar que el porcentaje de las que han sido aprobadas por el pueblo es muy reducido, puesto que la tendencia dominante en la sociedad suiza parece ser la de conservar el statu quo y rechazar las propuestas de modificación(36). Esto no obstante, a pesar de que las iniciativas populares no sean aprobadas, pueden ejercer una considerable influencia

(31) GIANNI, Matteo: "Una visión de Europa occidental: reflexiones sobre la integración de los musulmanes en sociedades secularizadas", en RUIZ VIEYTEZ, Eduardo y URRUTIA, Gorka (eds.): Derechos humanos y diversidad religiosa, Alberdania, San Sebastián, 2010, pág. 99.

(32) FUND, John: op. cit., pág. 60.

(33) LANGER, Lorenz: "Panacea or Pathetic Fallacy? The Swiss Ban on Minarets», en Vanderbilt Journal of Transnational Law, núm. 43-4, 2010, pág. 868.

(34) PROIETTO, Natasha: «Mountains and minarets», en HistoryToday, núm. 60-4, 2010, pág. 6.

(35) PETERS, Anne: «El referéndum suizo sobre la prohibición de minaretes», en Teoría y Realidad Constitucional, núm. 25, 2010, pág. 431; GIANNI, Matteo: op. cit., pág. 98.

(36) KRIESI, Hanspeter y TRECHSEL, Alexander: op. cit., pag. 57; PROIETTO, Natasha, op. cit., pág. 6. 
en la agenda política helvética (37). De hecho, las iniciativas populares sirven para incluir en la agenda peticiones que, a juicio de los promotores, apenas reciben atención en la política partidaria o institucional, y su aprobación popular es cada vez mayor. Desde la Segunda Guerra Mundial, la cifra anual de iniciativas se ha triplicado y la cuota de aprobación ha subido del 0 al $20 \%$, lo que numéricamente al menos es un cambio considerable que aparentemente refleja la pérdida de confianza en la política tradicional.

Un problema que plantea este creciente número de iniciativas populares y la tendencia creciente del pueblo a aprobarlas es que una mayor frecuencia de este tipo de votaciones produce una tensión política no siempre positiva ni cohesionadora para la sociedad. El problema estructural del cortoplacismo en la democracia representativa adquiere aquí una dimensión mayor por cuanto las urnas dirimen en ocasiones temas de calado moral o político sin permitir la distancia temporal mínima entre los diversos tipos de convocatorias(38). Un segundo problema, según Freiburghaus, es que todo hace indicar que las iniciativas populares se utilizan cada vez más para resaltar el perfil político de los partidos, subrayando la polémica concreta de cada caso y no tanto los aspectos más profundos o a largo plazo de cada tema. Ello provoca que haya una mayor dosis de emocionalidad en la toma de las decisiones y menor atención a las consecuencias futuras de las mismas (39).

Una buena parte de esta evolución populista relativamente reciente de las iniciativas populares responde a la transformación de uno de los cuatro partidos tradicionales del sistema político helvético. Los antecedentes del SVP hay que buscarlos en el Partido de los Agricultores, Comerciantes e independientes (BGB), fundado en 1936. El partido se alineó desde el principio en el llamado "bloque burgués" como un partido de corte conservador que aspiraba a representar los intereses de los pequeños agricultores y comerciantes frente a los grandes negocios y el capital. Tras la Segunda Guerra Mundial, el BGB contribuyó, junto a los Partidos Socialista, Radical y Democristiano, a la consolidación del sistema suizo de consenso político, crecimiento económico y acuerdos sociales. Tras una fusión con el Partido Democrático de Glaris y de Grisones, el partido cam-

(37) MOECKLI, Daniel: "Of Minarets and Foreign Criminals: Swiss Direct Democracy and Human Rights", en Human Rights Law Review, núm. 11-4, 2011, pág. 777.

(38) Es por ello que algunos autores proponen establecer un plazo de 5 años antes de celebrar un referéndum en los casos en que éste tenga relación con acontecimientos trágicos, a fin de evitar que el debate se mediatice y se enfríen las emociones: GONIN, Luc: op. cit., págs. 168-169. Un problema adicional será el de definir tales casos a priori.

(39) FREIBURGHAUS, Dieter: "Soberania popular o participación ciudadana», en Swissinfo.ch. 2015. Disponible en www.swissinfo.ch/democraciadirecta/punto-de-vista_soberan\%C3\%ADa-popular-oparticipaci\%C3\%B3n-ciudadana/41144642 
bió de nombre en 1971 para adoptar el actual (SVP-UDC). Esta fusión orientó el partido hacia el centro y lo abrió a posiciones social-liberales, con un apoyo medio sostenido algo superior al $10 \%$ del electorado.

Un cambio importante en la evolución del SVP ocurrió en 1977 con la Ilegada de Christoph Blocher al liderazgo del partido en Zurich. Este hecho marca un cambio de la organización y en las estrategias del SVP, que fue acompañado de cierto éxito electoral. Este mismo éxito se notará de modo progresivo a nivel federal en la medida en que el partido adopte agendas centradas en los temas de más calado populista como la inmigración o las diversidades no tradicionales de Suiza. Todo ello conduce al SVP a situarse como la fuerza más votada en las elecciones federales en los últimos diez años y a aumentar su cuota de voto hasta consolidarse por encima del 20\%. Al mismo tiempo, ejerce una considerable influencia en la agenda política, en ocasiones a través de las iniciativas populares que ya hemos visto, y con las que puede sortear su carácter minoritario en las instituciones federales. Hay que reconocer el éxito organizativo y dinamizador del SVP en este sentido, sobre todo a partir del siglo XXI (40).

Esta tendencia reciente impulsada por el éxito de una formación política que ha abandonado el consenso tradicional de la posguerra, ha conducido en definitiva a la adopción de iniciativas populistas que son vulneradoras de los derechos humanos (41), que tienen un impacto negativo sobre determinada suerte de minorías (42) o que incluso algunos califican como absolutistas (43). Voluntaria o involuntariamente esta dinámica puede conducir a un debilitamiento de las instituciones bajo el dogma de que la mayoría siempre tiene la razón, lo que podría conducir en la práctica a un sistema dirigista o autoritario (44).

\section{IV.3. Las contradicciones normativas}

Las dificultades que plantea el sistema suizo de democracia semidirecta no solo presentan naturaleza política, sino que también se extienden a aspectos jurídicos. El principal problema es la posibilidad de que el pueblo ratifique por vía de referéndum normas que entren en contradicción con normas internacionales, lo que sucederá con carácter gene-

(40) MOECKLI, Daniel: op. cit., pág. 780.

(41) MALINVERNI, Giorgio: op. cit., págs. 453-454.

(42) CHRISTMANN, Anna y DANACl, Deniz: op. cit., pág. 155.

(43) SUMMERMATTER, Stefania: "¿Y si el pueblo no siempre tuviera razón?», en Swissinfo.ch, 2014, Disponible en www.swissinfo.ch/democraciadirecta/democracia-directa_-y-si-el-pueblo-nosiempre-tuviera-raz\%C3\%B3n-/38599802

(44) SUMMERMATTER, Stefania: op. cit. 
ral cuando la iniciativa adoptada vulnere cualquier tratado internacional del que Suiza sea parte. Por el contrario, la aprobación de nuevas normas constitucionales que vayan en contra de otras disposiciones del mismo rango podría entenderse solucionada por el principio favorable a la ley posterior. Nótese en este sentido que en el Derecho constitucional suizo no existe el concepto de normas constitucionales inconstitucionales (45), de forma que un nuevo precepto constitucional puede entenderse como una norma especial o como una restricción de los derechos garantizados en otros artículos constitucionales (46), puesto que no existe una relación de jerarquía entre las diversas disposiciones de la Constitución (47).

Las iniciativas populares consisten siempre en propuestas de reforma constitucional y la Constitución suiza no establece más límites materiales para su reforma que el que contienen las normas imperativas de Derecho internacional, como señalan los artículos 193 y 194 en relación con la revisión total o parcial respectivamente. El artículo 139 regula el procedimiento que siguen las iniciativas populares, estableciendo que deben recibir el apoyo de 100.000 ciudadanos suizos en el plazo de 18 meses. En añadidura, la Asamblea federal determina si la iniciativa viola los principios de unidad de forma o de unidad de materia o si afecta a las normas imperativas de Derecho internacional, en cuyo caso la iniciativa será declarada inválida. Si no concurre ninguno de estos supuestos, la iniciativa debe someterse a la votación popular, aunque la Asamblea Federal emitirá una determinada recomendación de voto a los ciudadanos. La explicación de que este escrutinio sea competencia del Parlamento y no de un órgano de naturaleza judicial está en el ensalzamiento de la soberanía popular propio del régimen político suizo. Para su aprobación definitiva, como sabemos, es preciso que la iniciativa obtenga una doble mayoría afirmativa, tanto entre los electores de la Federación en su conjunto como entre los cantones.

Puesto que es difícil que los promotores de una iniciativa popular incurran en defectos de unidad de forma o de materia, el filtro de las normas imperativas de Derecho internacional adquiere gran importancia en este procedimiento. En la actualidad, el concepto de ius cogens se entiende conformado por las normas internacionales indisponibles o sobre las que ninguna forma de derogación es posible(48). De acuerdo a lo es-

(45) MALINVERNI, Giorgio: op. cit., pág. 464.

(46) PETERS, Anne: op. cit., pág. 432; MOECKLI, Daniel, op. cit., pág. 783.

(47) MAHON, Patrick: "Minarets, droit international impératif et Convention européenne des droits de I’homme" en Journal of Sharia \& Law, núm. 45, 2014, pág. 71.

(48) DISTEFANO, Giovanni, "Le droit international public en péril», en Journal of Sharia \& Law núm. 45, 2011, pág. 78. 
tablecido por la jurisprudencia internacional, los Estados no solo están obligados a cesar cualquier comportamiento contrario al ius cogens, sino que también lo están a derogar las normas que resulten incompatibles con el mismo (49). En el caso suizo, hasta la fecha el Parlamento federal ha realizado una interpretación muy estricta de la expresión constitucional "normas imperativas de Derecho internacional», entendiendo que la misma se corresponde con la noción más estricta de Derecho imperativo o ius cogens(50). Ello explica que la Asamblea suiza apenas haya utilizado este argumento para declarar inválidas iniciativas populares presentadas por los ciudadanos (51).

Así, una vez que una iniciativa popular ha sido aprobada en referéndum por mayoría de votantes y de cantones, no existen remedios jurídicos contra la misma en el ámbito interno y solo cabría acudir a remedios del ámbito internacional. Sin embargo, sabemos que a través de esta suerte de iniciativas pueden vulnerarse derechos humanos internacionalmente reconocidos (52) que no formen parte del ius cogens en sentido estricto, quedando estos supuestos sin solución jurídica en el ordenamiento constitucional helvético.

Como señalábamos en el apartado anterior, la iniciativa «contra la inmigración masiva" contradecía acuerdos previamente adoptados con la UE (y aprobados en referéndum en 2000). Las otras tres iniciativas mencionadas explícitamente en dicho apartado suponen a su vez vulneraciones de derechos humanos $y$, por consiguiente, de normas internacionales que los reconocen y protegen, y que obligan al Estado suizo. Así, en 2004 se aprobó la iniciativa en favor de la cadena perpetua para los autores de graves ofensas sexuales o violentas, contraria al derecho a una revisión judicial regular previsto en el artículo 5.4 del CEDH. Por lo que respecta a la prohibición de construcción de nuevos minaretes, tanto la Asamblea

(49) Corte Internacional de Justicia, "Opinión Consultiva sobre las consecuencias jurídicas de la construcción de un muro en el territorio palestino ocupado", Opinión de 9 de Julio de 2004, ClJ Recueil 2004, paras. 150 y 151. DISTEFANO, Giovanni: op. cit., pág. 81.

(50) MAHON, Patrick: op. cit., pág. 73. DISTEFANO, Giovanni: op. cit., pág. 81. El artículo 53 de la Convención de Viena de 23 de mayo de 1969 sobre el Derecho de los Tratados, dispone que «(...) Para los efectos de la presente Convención, una norma imperativa de Derecho internacional general es una norma aceptada y reconocida por la comunidad internacional de Estados en su conjunto como norma que no admite acuerdo en contrario y que sólo puede ser modificada por una norma ulterior de derecho internacional general que tenga el mismo carácter».

(51) Así sucedió en el caso de la iniciativa popular "por una política de asilo razonable», ante la que el parlamento suizo consideró que vulneraba la prohibición de torturas o tratos crueles al proponer la expulsión a otros países de los solicitantes de asilo sin posibilidad de recursos. La prohibición de torturas es parte del Derecho internacional imperativo. La iniciativa fue declarada inválida el 14 de marzo de 1996: Documento FF 1993 I 1305. Mensaje del Consejo federal de 22 de junio de 1994: Documento FF 1994 III 1471.

(52) KRZYWOSZYNSKI, Przemyslaw: "The Problem of Human Rights in Direct Democracy», en Bajo palabra. Revista de filosofía, núm. 9, 2014, págs. 95-102. 
federal (53) como el Directorio (54), y la práctica totalidad de la doctrina (55), señalaron que la iniciativa era contraria a la libertad de religión y la no discriminación recogidas en los artículos 9 y 14 del CEDH o 18, 2 y 26 del PICDP (56). De la misma forma se pronunciaron algunos órganos internacionales como el Consejo de Derechos Humanos de las Naciones Unidas (57), el Comité de Derechos Humanos de las Naciones Unidas (58) o la Asamblea Parlamentaria del Consejo de Europa(59). Finalmente, la iniciativa para la repatriación de criminales extranjeros, aprobada en referéndum en el año 2010 resulta también contraria a las normas garantistas del CEDH y del PIDCP, como declaró en su momento la Asamblea fede$\operatorname{ral}(60)$.

En todos estos casos se produce una contradicción entre la reforma popular de la Constitución y el respeto de Suiza a las obligaciones adquiridas internacionalmente, particularmente el respeto a derechos humanos que no forman parte del reducido concepto de ius cogens. El ejecutivo suizo ha reconocido que la mayoría de las normas del CEDH no forman parte del Derecho imperativo al que se refiere el artículo 53 de la Convención de Viena de 23 de mayo de 1969 sobre el Derecho de los Tratados (61). Algunos autores consideran que esta forma de razonar es errónea por no considerar la primacía del Derecho Internacional sobre el Derecho interno (62). Sin embargo, en el ordenamiento suizo la relación entre ambas esferas no es plenamente nítida. La Constitución federal señala que la Confederación y los Cantones «respetarán» el Derecho internacional (art. 5.4), pero no se establece una clara relación jerárquica entre ambos tipos de normas. Sí puede colegirse del tenor de los artícu-

(53) Decisión de la Asamblea Federal de 12 de junio de 2009, Documento FF 20093903.

(54) Mensaje del Consejo Federal de 27 de agosto de 2008: Documento FF 2008 6923, pp. 6949 y ss.

(55) MAHON, Patrick : op. cit., pág. 75; HIRTER, Hans, op. cit., pág. 13; LANGER, Lorenz, op. cit., pág. 882.

(56) PETERS, Anne, op. cit., pág. 431; HOTTELIER, Michel y MARTENET, Vincent : «La practique Suisse relative aux droits de I'homme 2006", en Revue suisse de Droit international et européen, 2007-2, 2007, pág. 272.

(57) Consejo de Derechos Humanos, Resolución 13/16, "La lucha contra la difamación de las religiones", de 25 de marzo de 2010, Documento A/HRC/RES/13/16, para. 8.

(58) Comité de Derechos Humanos, Examen de los informes presentados por los Estados partes con arreglo al artículo 40 del Pacto; Observaciones finales del Comité de Derechos Humanos; Suiza (Documento CCPR/C/CHE/CO/3, de 3 de Noviembre de 2009, para. 8.

(59) Asamblea Parlamentaria del Consejo de Europa, Resolución 1743 (2010), «Islam, Islamism and Islamophobia in Europe», de 23 de junio de 2010, para. 13.

(60) Mensaje del Consejo Federal de 24 de junio de 2009, Documento FF 2009 4571, p. 4577.

(61) Mensaje del Consejo Federal de 25 de octubre de 2006, Documento FF 2006 8481, p. 8485.

(62) HOTTELIER, Michel y MARTENET, Vincent : "La practique Suisse relative aux droits de I'homme 2008", en Revue suisse de Droit international et européen, 2009-3, 2009, pág. 433. 
los 193 y 194 de la Constitución que por encima de ésta solamente se situarían las normas imperativas de Derecho internacional, pero no el conjunto de tratados de los que Suiza es parte, incluso en materia de derechos humanos (63). A ello se añade la circunstancia de que decisiones como las ya referidas se han tomado por el electorado a sabiendas de que contradicen normas internacionales de derechos humanos $u$ otros tratados, puesto que las instituciones federales habían advertido de ello con anterioridad a la votación. El principio de separación de poderes y la relevancia que en el modelo constitucional suizo tiene el principio de soberanía popular imposibilitan que cualquier tribunal interno se vea con capacidad de revisar una norma adoptada a través de este proceso, lo que reduce la única posibilidad de encontrar remedios jurídicos al plano institucional internacional.

Frente a estas contradicciones normativas, se han propuesto algunas soluciones que hasta la fecha no han encontrado eco o acomodo en el sistema suizo por razones fundamentalmente políticas. De hecho, la actividad de las instituciones suizas en relación con esta cuestión cuya relevancia parece ir en aumento ha sido muy limitada y prudente (64). En un plano teórico, la solución más limpia jurídicamente pasaría por que Suiza denunciara aquellos tratados internacionales que resulten inconsistentes con posteriores reformas constitucionales. Sin embargo, en el caso de normas internacionales como el PIDCP, esto no es técnicamente posible (65) y en el del CEDH no lo sería políticamente (66).

Otro tipo de soluciones pasan por extender el contenido de los criterios de invalidez, y en particular el significado atribuido a la expresión «normas imperativas de Derecho internacional». Una interpretación más amplia de este concepto permitiría identificarlo no solo con el ius cogens en sentido estricto sino con el conjunto de normas internacionales de derechos humanos, o al menos con las disposiciones de tratados

(63) Sobre la relación entre leyes federales y tratados internacionales en el ordenamiento jurídico suizo, véase RUIZ VIEYTEZ, Eduardo: "Democracia y religión. Problemas derivados de la decisión suiza de prohibir los minaretes", Revista de Derecho Político, núm. 87, 2013, págs. 261-271.

(64) El Directorio elaboró en 2010 dos informes sobre la situación creada a raíz de la iniciativa de prohibición de los minaretes, en los que se trata esta cuestión y se estudian las posibles soluciones a la misma: "La relation entre droit international et droit interne», Rapport du Conseil fédéral du 5 mars 2010, Documento FF 2010-2067; y «Rapport additionnel du Conseil fédéral au rapport du 5 mars 2010 sur la relation entre droit international et droit interne», du 30 mars 2011, Documento FF 2011-3401.

(65) El Pacto no contiene cláusulas que regulen el mecanismo de denuncia. El Comité de Derechos Humanos ha señalado que los Estados parte no pueden retirarse del mismo una vez ratificado: Comité de Derechos Humanos, Comentario General núm. 26, "Continuidad de las obligaciones", Comentario de 8 de Diciembre de 1997, Documento CCPR/C/21/Rev.1/Add.8/Rev.1.

(66) Mensaje del Consejo Federal de 7 de junio de 2004, Documento FF 2004 3077, p. 3086. 
como el PIDCP y el CEDH (67). Así, frente a quienes insisten que la Constitución se refiere solamente al concepto internacional (68), hay quienes consideran que la noción constitucional puede ser interpretada más ampliamente, incluyendo en la misma las normas fundamentales de Derecho internacional (69).

Otras posibles soluciones pasarían por establecer la primacía del Derecho internacional sobre cualquier norma interna, lo que podría encontrar una base jurídica en el artículo 190 de la Constitución(70). En la misma línea, se ha propuesto también considerar inejecutables o inaplicables las normas constitucionales que contradigan obligaciones internacionales que es imposible denunciar(71). Finalmente, otros autores proponen asignar al Tribunal Federal o a otro órgano judicial imparcial, competencias en materia de admisibilidad o validez de las iniciativas populares(72), aunque una medida de este tipo encaja mal en un sistema político con una cultura tan específica en la que prima la voluntad popular y una desconfianza tradicional hacia las decisiones judiciales. En este sentido, la propia cultura política de Suiza genera a su vez problemas y contradicciones en la utilización de los mecanismos de democracia directa.

\section{IV.4. La cultura política suiza}

Desde otras sociedades, puede resultar difícil de entender que el pueblo suizo apruebe en referéndum decisiones que han sido rechazadas por las instituciones centrales y casi todos los partidos políticos que pueden representar juntos a tres cuartas partes del electorado. Sin duda, en ello tiene mucho que ver la cultura política tradicional de este país, pero debe también entenderse que la influencia es recíproca, de forma que esa misma cultura política se ve a su vez modelada por la existencia de mecanismos de democracia directa. Así, el uso habitual del referéndum provoca que los partidos políticos ejerzan sobre la sociedad una menor in-

(67) CANÇADO, Antonio: «The expansion of the material content of jus cogens: the contribution of the Inter-American Court of Human Rights», en SPIELMANN, Dean; TSIRLI, Marialena y VOYATZIS, Panayotis (eds.): The European Convention on Human Rights, a living instrument: essays in honour of Christos L. Rozakis Bruylant, Bruselas, 2011, págs. 27-41.

(68) HANGARTNER, Yvo y KLEY, Andreas: Die demokratischen Rechte in Bund und Kantonen der schweizerischen Eidgenossenschaft, Schulthess, Zurich, 2000, págs. 227-228.

(69) MALINVERNI, Giorgi:, op. cit., pág. 461.

(70) MALINVERNI, Giorgio: op. cit., pág. 461.

(71) MAHON, Patrick: op. cit., pág. 75.

(72) SUMMERMATTER, Stefania: op. cit.; MALINVERNI, Giorgio: op. cit., pág. 462. 
fluencia que en otros países (73) y que el comportamiento del electorado sea más impredecible(74). En realidad, el sistema político suizo, basado sobre una cultura de consenso entre las principales fuerzas políticas, ha colocado al electorado como potencial oposición política frente a las instituciones federales. A través del peculiar sistema de gobierno de Suiza y de la democracia directa, la oposición se residencia fuera del Parlamento y se ejerce por el electorado, otorgando a éste un papel preeminente a cambio de reducir los límites a su capacidad de decisión.

En efecto, los ciudadanos controlan normalmente a sus representantes a través del voto y las instituciones representativas se controlan entre ellas. Sin embargo, no es claro quién puede controlar a los protagonistas de un instrumento participativo. Del mismo modo que no es posible controlar políticamente un resultado electoral, resulta difícil un control de las normas o decisiones adoptadas por el electorado. Uno de los problemas de la democracia directa es que enajena el control político de aquellos sujetos que, como el parlamento, sí pueden ser objeto de control(75). Así, en Suiza existe una tendencia a considerar la voluntad del pueblo como sacrosanta, incluso si su compatibilidad con el Derecho internacional es más que cuestionable(76). La idea de que una decisión popular mayoritaria sea jurídicamente incorrecta (o incluso inconstitucional) resulta extraña en la cultura política suiza. Ello tiene que ver con la conformación histórica del imaginario nacional suizo, que conlleva un rechazo secular suizo a los jueces (particularmente los jueces extranjeros) o a las élites domésticas.

El imaginario suizo idealiza una sociedad igualitaria, autárquica, no elitista (77) y autosuficiente que proviene del mito fundacional de 1291, dentro de la lucha por la independencia del poder imperial. Este autogobierno está presidido por una idea comunitarista de participación directa en la toma de decisiones, un rechazo del elitismo, y un recelo de las instancias judiciales en beneficio del respeto a las decisiones populares. Ello ha conducido a un modelo político consensual, una presidencia rotatoria ciertamente débil y una democracia militante en cuanto a los aspectos participativos(78). En este marco, una hipotética condena a Suiza por

(73) LADNER, Andreas: «Political Parties», en KLÖTI Ulrich et al. (eds.): Handbook of Swiss Politics, 2. ${ }^{a}$ ed., Neue Zürcher Zeitung, Zurich, 2007, pág. 309.

(74) KRIESI, Hanspeter YTRECHSEL, Alexander: op. cit., pag. 121.

(75) RAMÍREZ NARDIZ, Alfredo: op. cit., pág. 207.

(76) HALLER, Walter: The Swiss Constitution in a comparative context, Dike, Zurich, 2009, pág. 61.

(77) CHOLLET, Antoine : Défendre la démocratie directe. Sur quelques arguments antidémocratiques des élites suisses, Presses polytecniques et universitaires romandes, Lausana, 2011.

(78) PROIETTO, Natasha: op. cit., pág. 5. 
parte de un tribunal internacional por la adopción de una iniciativa popular que pudiera violar obligaciones internacionales sería recibida como una injerencia externa ilegítima (79), lo que no hace sino enfatizar a su vez el problema de las contradicciones normativas al que aludíamos en el apartado anterior.

Otra de las características específicas del sistema suizo, su pluralidad fundacional lingüística y religiosa, no ha supuesto en este ámbito un factor relevante. La identidad nacional suiza y un evidente patriotismo descansan hoy, sobre todo, en una cultura política construida a partir de un sistema constitucional peculiar basado en el consenso político, el federalismo, la democracia directa y valores como el sentido del orden, de la propiedad, y la ética del trabajo(80). Al mismo tiempo, Suiza representa el arquetípico de nación política (Willensnation) (81). Los factores internos de división identitaria (lengua, religión, clase social) no impiden compartir una misma cultura política (82), aunque los grupos lingüísticos sí muestran algunas tendencias divergentes en materia de comunicación y opinión pública(83). Si bien las divisiones religiosas fueron tradicionalmente más relevantes en el comportamiento electoral de los suizos, y aún hoy marcan grandes diferencias en los sistemas de partidos de cada cantón (84), en las últimas décadas las diferencias en el comportamiento electoral de la zona francófona frente a la germanófona se han acentuado(85), particularmente en el caso de alguno de los referendos que afectaban a iniciativas sensibles para los derechos humanos.

Esto no obstante, permanece firmemente consolidada la idea de la prevalencia de la voluntad popular sobre cualquier otra instancia normativa o judicial extranjera, lo que supone en ocasiones legitimar decisiones

(79) LANGER, Lorenz: op. cit., pág. 922.

(80) BÜCHI, Christophe : Mariage de raison. Romands et Alémaniques: une histoire suisse, Éditions Zoé, Ginebra, 2001, pág. 289.

(81) MEUNE, Manuel : «Pluralisme identitaire et nation unitaire en Suisse. Les discours des acteurs politiques locaux dans les cantons bilingues à I'aune du débat québécois", en Swiss Political Science Review, núm. 17-3, 2011, pág. 310; EUGSTER, Beatrice y STRIJBIS, Oliver : "The Swiss: A Political Nation?", en Swiss Political Science Review,núm. 17-4, 2011, pág. 394.

(82) LINDER, Wolf: Swiss Democracy. Possible Solutions to Conflict in Multicultural Societies (2. ed), Macmillan Press, Londres, 1998, pág. 25.

(83) IPPERCIEL, Donald : "La Suisse: un cas d'exception pour le nationalisme?», en Swiss Political Science Review, núm. 13-1, 2007, pág. 62.

(84) KLÖTI, Ulrich:«Kantonale Parteiensysteme - Bedeutung des kantonalen Kontexts für die Positionierung der Parteien", en KRIESI, Hanspeter, LINDER, Wolf y KLÖTI, Ulrich (dirs.). Schweizer Wahlen 1995, 1998, Haupt, Berna, pág. 49; KRIESI, Hanspeter : Le système politique suisse, Economica, Paris, 1998, pág. 149.

(85) PAPADOPOULOS, Yannis: "Connecting Minorities to the Swiss Federal System: A Frozen Conception of Representation and the Problem of "Requisite Variety», en Publius, núm. 32-3, 2002, págs. 62-63. 
contrarias a los derechos humanos con base en la legitimidad de un referéndum. Ello resulta particularmente oneroso para determinadas minorías o colectivos que no han participado en la construcción histórica del sistema. Así, debe recordarse que las mujeres no vieron reconocido su derecho al voto hasta el año 1971 y que la misma decisión había sido rechazada en referéndum popular (exclusivamente masculino) en el año 1959. Más graves han sido las consecuencias hasta la fecha para otros colectivos como el de las personas extranjeras o determinadas minorías religiosas. En efecto, el sistema de doble mayoría requerido para la aprobación de determinados referendos pretendía ser uno de los dos instrumentos que garantizaba una salvaguarda de la pluralidad interna (siendo el otro la representación paritaria de los cantones en la cámara alta). Sin embargo, la creciente utilización del referéndum y el sistema de doble mayoría han tenido efectos perversos en la representación de otras minorías que han aparecido más tarde como fruto de las transformaciones sociales (86). La aprobación de las iniciativas populares que dañan los derechos humanos de los musulmanes o de determinados colectivos extranjeros son buena prueba de ello. Y la cultura política suiza impide una revisión constitucional o judicial de dichas decisiones, incluso en el ámbito internacional, de forma que una hipotética sentencia correctora del Tribunal Europeo de Derechos Humanos sería recibida en estos casos como una intromisión ilegítima más que como una garantía de defensa de los derechos humanos (87).

\section{Conclusión}

Si bien el referéndum se presenta como el mecanismo de democracia directa que mejor puede servir a una mayor participación de los ciudadanos en la propuesta y toma de decisiones políticamente relevantes, la experiencia suiza nos enseña la necesidad de adoptar una serie de cautelas a la hora de proceder a dicha ampliación. En primer lugar, es necesario dosificar la llamada a la participación activa de la ciudadanía de una manera progresiva y proporcionada, de forma que no se produzca a medio plazo un cansancio o saturación del electorado que redunde en una baja participación en los referendos. Ello aconsejaría al mismo tiempo dotar a los referendos de carácter decisorio, evitando las consultas sobre aqueIlos aspectos o debates sobre los que exista un consenso político amplio que presumiblemente se extienda también a la ciudadanía. De la expe-

(86) SÁENZ ROYO, Eva: op. cit., págs. 95-98; PAPADOPOULOS, Yannis: op. cit., pág. 64.

(87) PETERS, Anne : op. cit., pág. 437. 
riencia suiza se deduce que un cierto grado de tensión en las decisiones a adoptar fomenta la participación en los referendos.

De igual modo, es preciso impedir que el recurso al referéndum sea utilizado en beneficio de agendas populistas que puedan dar lugar a contradicciones normativas o políticas. Deben establecerse límites materiales y jurídicos claros que incluyan, por ejemplo, una validación previa del objeto de la consulta. Esta validación podría ser hecha por un órgano que se identifique como imparcial (no necesariamente de naturaleza judicial) y deberá servir también para hacer innecesario un hipotético control posterior a la expresión de la voluntad popular, que sería muy inconveniente políticamente. En todo caso es preciso evitar que la voluntad popular sea percibida como superior jurídicamente a las normas fundamentales de derechos humanos y a los principios básicos que conforman el núcleo duro del sistema constitucional. Ello no impide que puedan ser sometidas a iniciativa popular reformas de la propia Constitución, pero siempre que no colisionen con los valores fundamentales del sistema democrático que desde luego incluirán en todo caso el conjunto de los derechos humanos internacionalmente garantizados, así como con cualquier obligación jurídica adquirida por el Estado en el ámbito internacional.

Las tentaciones de recurrir a un populismo contrario a los derechos fundamentales también deberán ser combatidas estableciendo procedimientos certeros y pausados que permitan distanciar las convocatorias populares mediante periodos de enfriamiento que faciliten debates serenos y fomenten a su vez la participación. La administración con prudencia política de este precioso instrumento de participación popular solo puede ir en beneficio de la madurez democrática de cualquier sociedad, sin olvidar en todo momento que, como señalaba Benjamin Constant, la voluntad de todo un pueblo no puede convertir en justo aquello que es de por sí injusto.

\section{Referencias}

BÜCHI, Christophe: Mariage de raison. Romands et Alémaniques: une histoire suisse, Éditions Zoé, Ginebra, 2001.

CABEZA, Laura y GOMEZ FORTES, Braulio: «Referéndums sin ciudadanos. El caso del referendo para la reforma del Estatuto de Autonomía andaluz», en Reis: Revista española de investigaciones sociológicas, núm. 130, 2010, pp. 11-40.

CANÇADO, Antonio: "The expansion of the material content of jus cogens: the contribution of the Inter-American Court of Human Rights», en SPIELMANN, Dean;TSIRLI, Marialena y VOYATZIS, Panayotis (eds.): The 
European Convention on Human Rights, a living instrument: essays in honour of Christos L. Rozakis Bruylant, Bruselas, 2011, pp. 27-46.

CHOLLET, Antoine: Défendre la démocratie directe. Sur quelques arguments antidémocratiques des élites suisses, Presses polytecniques et universitaires romandes, Lausana, 2011.

CHRISTMANN, Anna y DANACl, Deniz: «Direct Democracy and Minority Rights. Direct and Indirect Effects on Religious Minorities in Switzerland", en Politics and Religion, núm. 5-1, 2012, pp. 133-160.

DISTEFANO, Giovanni : "Le droit international public en péril», en Journal of Sharia \& Law, núm. 45, 2011, pp. 78-83.

EUGSTER, Beatrice y STRIJBIS, Oliver: "The Swiss: A Political Nation?», en Swiss Political Science Review, núm. 17-4, 2011, pp. 394-416.

FLEINER, Thomas; MISIC, Alexander yTÖPPERWIEN, Nicole: Constitutional Law in Switzerland. 2. ${ }^{a}$ ed., Wolters Kluwer, La Haya, 2012.

FREIBURGHAUS, Dieter: «Soberania popular o participación ciudadana», en Swissinfo.ch. 2015. Disponible en www.swissinfo.ch/democraciadirecta/punto-de-vista_soberan\%C3\%ADa-popular-o-participaci\%C3\%B3nciudadana/41144642

FUND, John: "Swiss Stunner», en The American Spectator, febrero 2010, pp. 60-61.

GARÇON, François: Le modèle Suisse. 2. ${ }^{\mathrm{a}}$ ed., editions Perrin, Paris, 2011.

GIANNI, Matteo: "Una visión de Europa occidental: reflexiones sobre la integración de los musulmanes en sociedades secularizadas», en RUIZ VIEYTEZ, Eduardo y URRUTIA, Gorka (eds.): Derechos humanos y diversidad religiosa, Alberdania, San Sebastián, 2010, pp. 81-104.

GÓMEZ CAMPOS, Steffan: «Mecanismos de democracia directa en América Latina: Una revisión comparada», en Revista de Derecho Electoral, núm. 10, 2010, pp. 1-36.

GONIN, Luc: Droit constitutionnel suisse. Fondements, institutions et défis, Schultthess, Ginebra, 2015.

GRISEL, Etienne: Initiative et référendum populaires. Traité de la démocratie semi-directe en droit suisse. $3 .^{a}$ ed., Staempfli editions, Berna, 2004.

HALLER, Walter, The Swiss Constitution in a comparative context, Dike, Zurich, 2009.

HANGARTNER, Yvo y KLEY, Andreas: Die demokratischen Rechte in Bund und Kantonen der schweizerischen Eidgenossenschaft, Schulthess, Zurich, 2000.

HIRTER, Hans (dir.) : Année politique Suisse 2009, Institut de science politique à la université de Berne, Berna, 2010.

HOTTELIER, Michel y MARTENET, Vincent : "La practique Suisse relative aux droits de I'homme 2006», en Revue suisse de Droit international et européen, 2007-2, 2007, pp. 269-314. 
HOTTELIER, Michel y MARTENET, Vincent: "La practique Suisse relative aux droits de I'homme 2008", en Revue suisse de Droit international et européen, 2009-3, 2009, pp. 431-464.

IPPERCIEL, Donald : "La Suisse: un cas d'exception pour le nationalisme?», en Swiss Political Science Review, núm. 13-1, 2007, pp. 39-67.

KLÖTI, Ulrich: "Kantonale Parteiensysteme - Bedeutung des kantonalen Kontexts für die Positionierung der Parteien», en KRIESI, Hanspeter, LINDER, Wolf y KLÖTI, Ulrich (dirs.): Schweizer Wahlen 1995, 1998, Haupt, Berna, pp. 45-72.

KRIESI, Hanspeter (dir.) : Citoyenneté et démocratie directe. Compétence, participation et décision des citoyens et citoyennes suisses, Editions seísmo, Zurich, 1993.

KRIESI, Hanspeter : Le système politique suisse, Economica, Paris, 1998.

KRIESI, Hanspeter y TRECHSEL, Alexander: The Politics of Switzerland. Continuity and change in a consensus democracy, Cambridge University Press, Cambridge, 2008.

KRZYWOSZYNSKI, Przemyslaw: «The Problem of Human Rights in Direct Democracy", en Bajo palabra. Revista de filosofía, núm. 9, 2014, pp. 95-102.

LADNER, Andreas: «Political Parties», en KLÖTI Ulrich et al. (eds.), Handbook of Swiss Politics, 2. ${ }^{a}$ ed., Neue Zürcher Zeitung, Zurich, 2007, pp. 309-334.

LANGER, Lorenz: "Panacea or Pathetic Fallacy? The Swiss Ban on Minarets", en Vanderbilt Journal of Transnational Law, núm. 43-4, 2010, pp. 863-951.

LINDER, Wolf: Swiss Democracy. Possible Solutions to Conflict in Multicultural Societies (2. ${ }^{a}$ ed), Macmillan Press, Londres, 1998.

MAHON, Patrick: "Minarets, droit international impératif et Convention européenne des droits de I'homme» en Journal of Sharia \& Law, núm. 45, 2014, pp. 71-77.

MALINVERNI, Giorgio: «Démocratie directe et droits de I'homme», en GOOD, AndreayPLATIDOPIS, Bettina(eds.):DirekteDemokratie:Herausforderungen zwischen Politik und Recht, Stämpfli, Berna, 2013, pp. 453-467.

MARENGHI, Patricia y ALCÁNTARA, Manuel: "Los mecanismos de la democracia directa», en Revista de Derecho Electoral, núm. 4, 2007, pp. 1-25.

MEUNE, Manuel : "Pluralisme identitaire et nation unitaire en Suisse. Les discours des acteurs politiques locaux dans les cantons bilingues à l'aune du débat québécois», en Swiss Political Science Review, núm. 17-3, 2011, pp. 308-335.

MOECKLI, Daniel: "Of Minarets and Foreign Criminals: Swiss Direct Democracy and Human Rights", en Human Rights Law Review, núm. 11-4, 2011, pp. 774-794.

PAPADOPOULOS, Yannis: "Connecting Minorities to the Swiss Federal System: A Frozen Conception of Representation and the Problem of "Requisite Variety" ", en Publius, núm. 32-3, 2002, pp. 47-66. 
PETERS, Anne: «El referéndum suizo sobre la prohibición de minaretes», en Teoría y Realidad Constitucional, núm. 25, 2010, pp. 429-438.

PRESNO LINERA, Miguel Ángel: "Causas jurídico-constitucionales de la desafección ciudadana hacia el sistema representativo", en TUR AUSINA, Rosario (dir.): SANJUÁN, Francisco Javier y CALABIUG, María Amparo (coords.): Problemas actuales del Derecho constitucional en un contexto de crisis, Comares, Granada, 2015, pp. 137-162.

PROIETTO, Natasha: "Mountains and minarets", en History Today, núm. 60-4, 2010, pp. 5-6.

RAMÍREZ NARDIZ, Alfredo: «Más participación igual a mejor democracia? Acerca de la crítica a la democracia participativa", en Revista de Derecho Político, núm. 94, 2015, pp. 183-218.

REQUEJO RODRÍGUEZ, Paloma: "Ciudadanos menores de edad", en Revista Española de Derecho Constitucional, núm. 99, 2013, pp. 201227.

RUIZ VIEYTEZ, Eduardo: «Democracia y religión. Problemas derivados de la decisión suiza de prohibir los minaretes", Revista de Derecho Político, núm. 87, 2013, pp. 253-288.

RUIZ VIEYTEZ, Eduardo: “¿Derecho a decidir en clave interna? el conflicto del Jura y el referéndum de 2013», en Revista d'Estudis Autonómics $i$ Federals, núm. 20, 2014, pp. 96-131.

SÁENZ ROYO, Eva: "La regulación y la práctica del referéndum en suiza. Un análisis desde las críticas a la institución del referéndum», en Revista de Estudios Políticos, núm. 171, 2016, pp. 71-104.

SÁNCHEZ FERRIZ, Remedio: «El pueblo de la Confederación Suiza: su significado constitucional y composición», en Revista de Derecho Político, núm. 95, 2016, pp. 11-38.

SARTORI, Giovanni: ¿Qué es la democracia?, Taurus, México DF, 2007.

SMITH, Graham: Democratic innovations. Designing institution for citizen participation, Cambridge University Press, Cambridge, 2009.

SOTO BARRIENTOS, Francisco: «Democracy as a form of state: Analysis of direct democracy' mechanisms regulated by the Swiss constitution", en Estudios Constitucionales, núm. 10-1, 2012, pp. 373-402.

SUMMERMATTER, Stefania: "¿Y si el pueblo no siempre tuviera razón?», en Swissinfo.ch, 2014, Disponible en www.swissinfo.ch/democraciadirecta/ democracia-directa_-y-si-el-pueblo-no-siempre-tuviera-raz\%C3\%B3n/38599802

TIERNEY. Stephen: Constitutional Referendums. The Theory and Practice of Republican Deliberation, Oxford Constitutional Theory, Oxford, 2012.

TORNAY, Bénédicte : La démocratie directe saisie par le juge. L'empreinte de la jurisprudence sur les droits populaires en Suisse, Schulthess, Ginebra, 2008. 
TRETTEL, Martina: «The Politics of Deliberative Democracy. A Comparative Survey of the "Law in Action" of Citizen Participation", en Revista de Derecho Político, núm. 94, 2015, pp. 85-114.

VÍRGALA FORURIA, Eduardo: "Crisis de la representación y democracia directa en España», en Asamblea: revista parlamentaria de la Asamblea de Madrid, núm. 29, 2013, pp. 11-25.

ZOVATTO, Daniel: "Las instituciones de la democracia directa a nivel nacional en América Latina: Un balance comparativo: 1978-2007», en $R e-$ vista de Derecho Electoral, núm. 4, 2007, pp. 1-51. 
LABURPENA: Azken urteotan, erreferenduma gehiago erabiltzea proposatu dute hainbat sektore sozial eta politikok, herritarrek parte hartzeko mekanismoa izan dadin eta gure sistemaren birsorkuntza demokratikoa ekar dezan. Europako testuinguruan, Suitzak erabiltzen du gehien erreferenduma. Suitzako esperientziak erakusten duenez, erreferenduma sarri erabiltzea ez dago arazo politiko eta juridikoetatik salbuetsita. Lehenengoen artean, hautesleen parte-hartzea txikia izaten dela, populismoa areagotu egiten dela eta, giza eskubideei eragin diezaieketen arren, herritarren erabakiak goresten dituen kultura politikoa eratzen dela aipa daiteke. Erreferendumean onartutako xedapenek nazioarteko arauei aurka egiten dietenean, zailtasun handiak agertzen dira arlo juridikoan; zehazki, giza eskubideen eremuan. Gure sistema politikoan erreferendumaren erabilera areagotzeko orduan, faktore horiek aintzat hartu behar dira.

GAKO HITZAK: Demokrazia. Erreferenduma. Parte-hartzea. Suitza. Zuzeneko demokrazia.

RESUMEN: En los últimos años varios sectores sociales y políticos han propuesto un mayor uso del referéndum como mecanismo de participación popular y de regeneración democrática de nuestro sistema. En el contexto europeo Suiza es el país que más profusamente hace uso del referéndum. Su experiencia suiza muestra que la utilización frecuente del referéndum no está exenta de problemas políticos y jurídicos. Entre los primeros pueden citarse la baja participación del electorado, el aumento del populismo y la configuración de una cultura política que ensalza las decisiones populares aun en los casos en los que éstas puedan afectar a los derechos humanos. En el plano jurídico se plantean importantes dificultades cuando las disposiciones aprobadas en referéndum contradicen normas de carácter internacional, en particular en el ámbito de los derechos humanos. Estos factores deben ser tenidos en cuenta a la hora de incrementar el uso del referéndum en nuestro sistema político.

PALABRAS CLAVE: Democracia. Referéndum. Participación. Suiza. Democracia directa.

ABSTRACT: In the last years, several social and political sectors have suggested a more frequent and efficient use of referendum as a mechanism for political participation and democratic regeneration in our system. Within the European context, Switzerland is the country that most frequently uses the referendum. Its experience shows that a frequent use of referendum is not free from political and legal problems. Among the political concerns, it can be mentioned ta low turnout, an emerging populism and a peculiar political culture that enshrines popular will even in the cases in which this might go against human rights. From the legal perspective, important difficulties can be found when clauses adopted by referendum go against international legal standards, particularly in the field of human rights. These problematic factors must be seriously considered in a possible increase of the use of referendum in our constitutional system.

KEYWORDS: Democracy. Referendum. Participation. Switzerland. Direct democracy. 